\title{
Regional Planning and Citizen Participation in South Korea: The Case of Chungbook Province
}

\author{
Choi, Byung-Dae, Dr., Seoul Development Institute, 216-14, Ronkyun-Dong, \\ Kangnam-Gu, Seoul 135-010, Korea; \\ Kent, Robert B., Prof. Dr., University of Akron, Department of Geography and \\ Planning, Akron, Ohio 44325-5005, USA
}

\begin{abstract}
Regional planning in Korea has seldom been influenced by the demands and pressures of interested groups or citizens. To remedy this and open up the planning process to citizen participation, the Korean government developed the Regional Development Regulations of 1981. This mechanism directs regional development planning and citizen participation in it.

The experience of the Chungbook Regional Development Plan (1981-1982) is characteristic of the present process of citizen participation in planning in Korea. The methods of insuring citizen participation are fourfold: the citizen advisory committee, the survey of citizens' opinions, the study conference, and the public hearing. Nonetheless, both planners and citizens often assess the participatory elements as being unsatisfactory.

Citizen participation in the planning process in Korea can be improved. Specific measures include the addition of a pre-plan phase to the current regional planning process. This phase would require widespread publicity informing citizens of the opportunity to participate in the planning process and improved mechanisms to elicit from citizens their views on the key issues of the regional plan before the decision making phase begins. Finally, the government needs to develop a long-term approach to improving citizen participation in the regional planning process. This should involve the development of training programs that advocate a bottom-up approach to planning based on grassroots citizen participation.
\end{abstract}

\section{Introduction}

The goals of this paper are to analyze citizen participation in the planning process in Chungbook Province, Korea and to search for more desirable alternatives to the present process of citizen participation in planning.

\section{Citizen Participation in Planning in Korea}

Traditionally, Korea has greatly limited the opportunity of citizen participation in the planning process. The pivotal reason for this situation is that a governor is appointed by central government (president). He appoints several committees as means of insuring citizen participation in the creation of a regional development plan, for example, the citizen advisory committee, the urban planning committee, the community development committee, and so on. Hence, the members of these committees are appointed by a government official rather than being selfselected or elected by the citizens. Therefore, their activities are very pro-government as well as passive. Also, the officials are characterized by authoritative thought and lack the attitude of service to the citizen. Traditionally, these things derive from the deplorable custom of putting government above people. A model portraying the principal actors in the planning process and their relationships is shown in Fig 1.

However, these tendencies are gradually changing. As the degree of the citizen's knowledge is gradually increasing, the attitude of citizens is changing from a passive attitude to an active attitude. Citizens have a reason to participate directly in the planning process since 


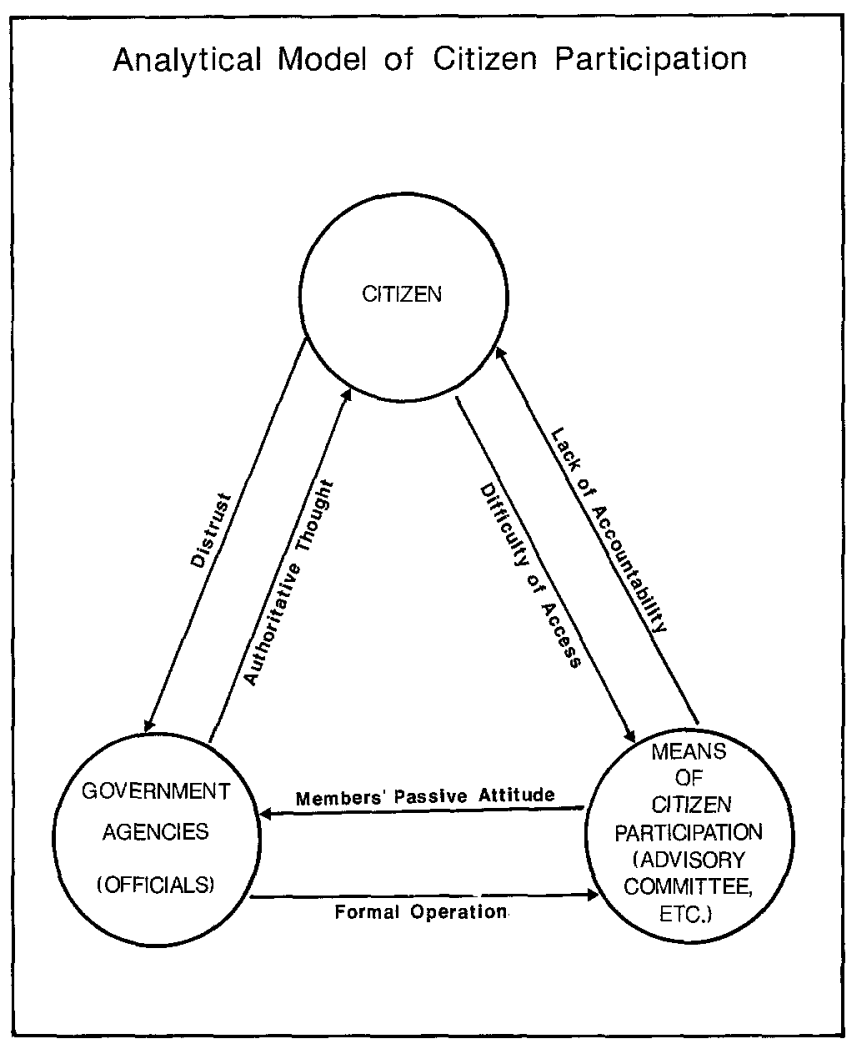

Fig 1 Analytical model of citizen participation

they are directly influenced by a new plan. Moreover, from the government's perspective, a plan which lacks citizens consensus is difficult to implement, and citizens may not cooperate or they may even actively resist the plan. For example, recent squatter and substandard housing removal

Fig 2 The map of Korea and Chungbook Province

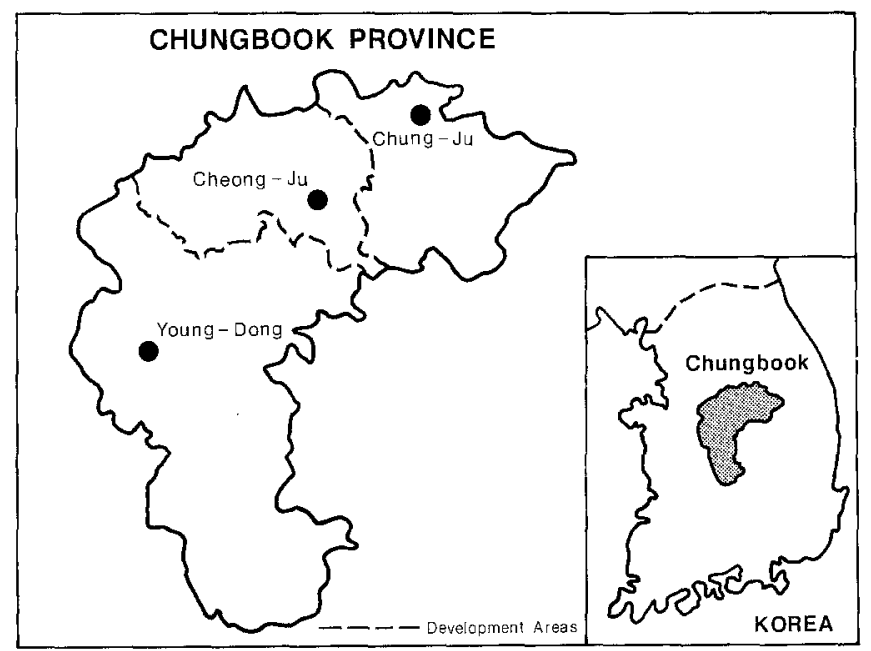

programs were stopped after a series of massive demonstrations took place protesting government policy on land sales and the provision of poor services ${ }^{1)}$.

Accordingly, in 1981 the government developed an institutional provision for citizen participation in regional development planninq. That is, government agencies have to incorporate citizen involvement in the creation of a regional development plan under the rules of the Regional Development Regulation ${ }^{2)}$. Nonetheless, the role of citizen participation in planning process is very weak because the great majority of citizens and officials have never experienced it.

\section{Citizen Participation in Chungbook Regional Development Plan}

Chungbook province is located in the center of South Korea, about $150 \mathrm{~km}$ from Seoul (Fig 2). The population of Chungbook is $1,445,000$, which is $3.8 \%$ of the national population. Total area of Chungbook is $7,436 \mathrm{~km}^{2}$, which occupies $7.5 \%$ of national area. The total number of households in Chungbook region is $292,000^{3}$. Per capita GRP (gross regional product) is very low compared to per capita GNP (gross national product). Overall, the degree of regional development is less than the national average and less than most other provinces ${ }^{4}$.

\section{Decision-Making Sequence}

As the degree of regional development of Chungbook region fell behind compared to the other regions, the government became concerned. So it launched the study for the Chungbook Regional Development Plan on October 16, 1981. The first advisory conference was held on December 14, 1981. Research concerning residents' attitudes was carried out from December 16 to December 24, 1981. An interim report was released in April, 1982. The second advisory conference was held on April 25, 1982 and the study conference was held on April 29,1982. The public hearing was held on June 30,1982. The final report was issued on July 30,1982 , less than one year after the initiation of the process ${ }^{5)}$. These processes are summarized in Fig 3.

\section{Methods of the Citizen Participation}

Methods of the citizen participation in Chungbook Regional Development Plan are fourfold. These include the citizen advisory committee, the survey, the study conference, and the public hearing. The Regional Development Regulation mandated that the citizen advisory committee be used as the method to secure citizen participation. Since that time, government agencies have had to consult with the citizen advisory committee.

As noted earlier, members of citizen advisory committee are appointed by the Chungbook governor. The 
number of members on the citizen advisory committee usually ranges from 30 to 40 . Their role is to represent the opinions of region's residents. In the case of Chungbook Regional Development Plan, the governor appointed 34 members. These consisted of 5 leaders of the "new village movement"6), 5 representatives of the business sector, 5 chiefs of the villages, 3 women leaders, 2 representatives of YWCA, 3 representatives of religious groups, 3 members of the Lions Club, and others ${ }^{7}$.

These individuals met twice as members of the advisory committee. The first conference was held on December 14, 1981. The purpose of this conference was to poll residents' ideas about the directions of a regional development plan. In this conference, committee members relay their requests to the planners and discuss comprehensive problems about the regional development plan. The second advisory conference was held on April 2, 1982. The purpose of this conference was to see whether the ideas presented by the committee in the first conference were reflected in the plan.

The survey of citizens' opinions is a second step in citizen participation. The government authorized the Environmental Planning Institute in Seoul National University to develop the survey to assist in the planning process in Chungbook Province. The Institute surveyed residents' opinions by randomly selecting 1,000 individuals who responded to a questionnaire and 1,000 for a personal interview ${ }^{8)}$.

The third step is the study conference. The goal of the study conference is to gather experts' opinions about the plan. In the case of Chungbook Regional Development Plan, the members of the study conference consisted of planning experts, professors, and regional residents. This conference was held on April 28, 1982. The members of study conference were selected and invited by the Chungbook governor.

The final phase in the process of citizen participation is the public hearing. The public hearing was held on June 30 , 1982. This was a large meeting in which all members of the advisory committee and the study conference participated. Also, everybody who has a concern about the plan can take part in the public hearing. The purpose of this hearing was for the public to finally examine the plan and discuss their opinions with planners. This meeting was held just before completion of the plan, and therefore, it was the last chance for citizens to participate in the decision-making process for the Chungbook Regional Development Plan.

\section{Evaluation}

Citizen advisory committee is one of the most widely used devices for citizen participation in public programs. But, too often, this device is not used well. In the case of the Chungbook Regional Development Plan, the advisory committee was weak and ineffective. First, the citizen advisory committee lacks responsibility to citizens in general because there is no institutional channel for

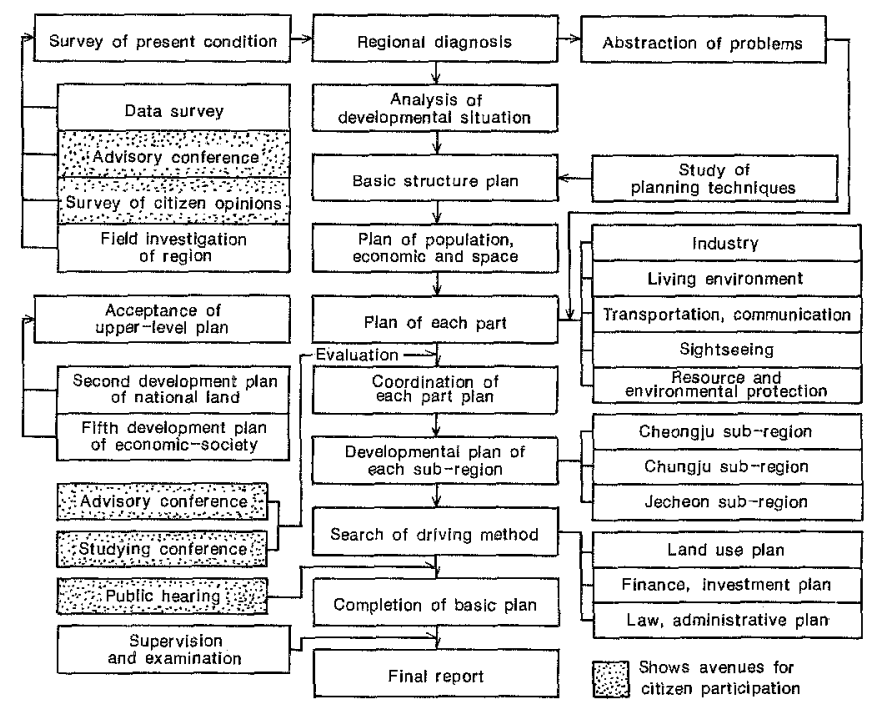

Fig 3 The planning process of comprehensive regional development plan in Chungbook Province

communication between citizens and advisory committee. Second, the members of advisory committee are appointed by the governor based on his own criteria. Thus, it is difficult to expect them to play the role of sound independent critics. As Milbrath argued "they can be manipulated easily by public officials to suit" the government's goals ${ }^{9)}$. Finally, government planning officials frequently ignore the advice and ideas that come from advisory committee. This is largely because the committee is established purely for the purpose of meeting the legal requirements for citizen participation by the Regional Development Regulation. The agency has no intention of listening seriously to the members of citizen advisory committee, and only grudgingly establishes committee.

Thus, the advisory committee has difficulties in furthering citizen participation because of the characteristics of its structure and membership. However, it is possible that the advisory committee could act as a decision-making supplement for planners by providing advice on plans, goals, or proposed decisions, and in practice some perform this function ${ }^{10}$.

The advantage of the citizen survey is that it represents a scientifically selected random sample of the population and can obtain an accurate representation of the views of all types of people. The information gathered may be used to improve services or to incorporate citizen views into planning, but often respondents do not realize that they are participating in the planning processes because they only make indirect statements of their opinions to the surveyors. Nevertheless, in Chungbook the survey was beneficial. Many results of the survey are reflected in the Chungbook Regional Development Plan. One shortcoming of the surveys is that they are not an adequate substitute for the dynamic interaction and development of ideas that can occur in face-to-face discussion ${ }^{11)}$. 


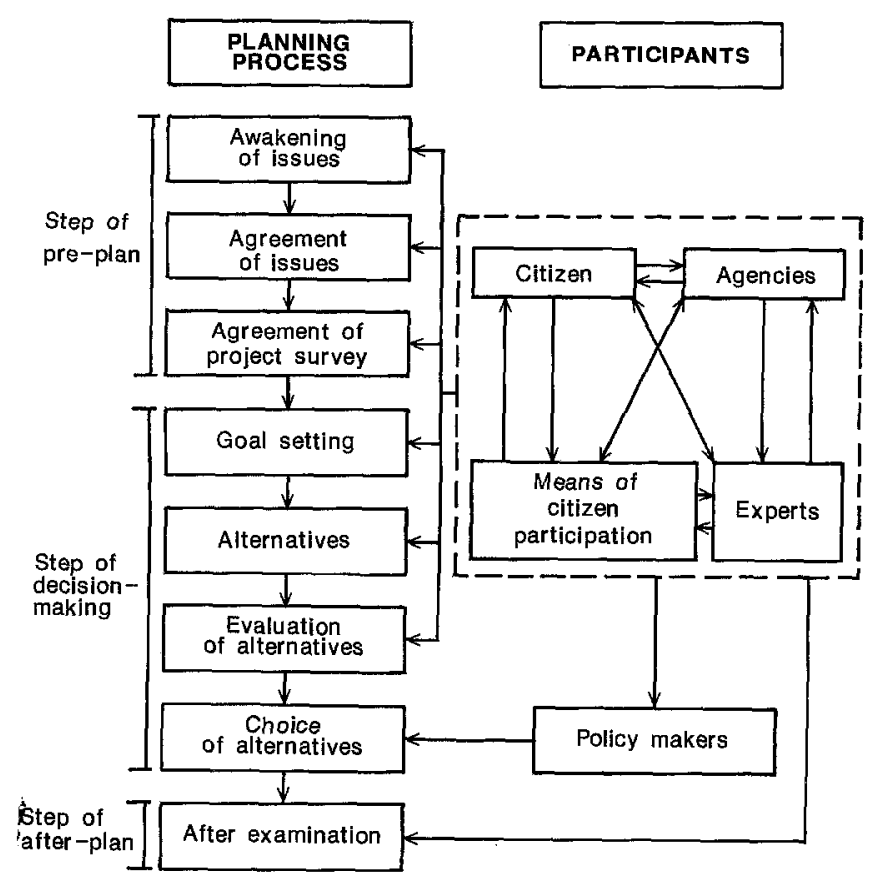

Fig 4 A new model of planning processes and the role of participants

The major purpose of the study conference is to provide experts' opinions on the plan. But there is problem in selecting of the experts. Like the citizen advisory committee, the members of study conference are selected by the Chungbook governor. So most of them are progovernment and tend to play a role as strong supporters rather than careful critics.

The public hearing is a method of effective citizen participation because this does not limit the scope of the participants. Anyone who is interested in the planning process can take part in the meeting. But there are also some problems. The responsible government agency is required to inform residents of the meeting. But the agency only notifies the citizen through the use of official gazettes and wall newspapers (posters). Thus, only a limited number of individuals are informed. Also, most citizens are not accustomed to citizen participation and do not even consider active participation. Furthermore, it is common for a hearing to be held after policy has already been agreed to by the government agencies involved in the decision. Accordingly, when a hearing does occur, input from the citizens only has a limited import. Finally, most of the people who appear at the hearings represent special interest groups. There is little or no incentive for the average citizen to come to the meeting or to make a statement at the hearing ${ }^{12)}$. And indeed, few citizens participated in the hearing for the Chungbook Regional Development Plan.

\section{Conclusions}

Korea does not have long history of citizen participation in planning and there are many problems which limit their effective participation. First, the planning period is very short, and it is difficult for constructive advice to be utilized by the planners. In the case of the Chungbook region, the planning period was about 8 months long, ranging from November 1981 to June 1982. In a comprehensive regional development plan like Chungbook Province Project, the short term of the planning period serves to limit a broad spectrum of constructive advice or criticism. Twelve months is suggested as the minimum acceptable period for the development of such a plan ${ }^{13)}$.

Several other problems can be identified. First, government agencies do not view citizen participation positively. They regard it as an obstacle to the decisionmaking process in the public sector and are annoyed if they must change the plan to incorporate citizens opinions. Second, government agencies have long been accustomed to the top-down approach to planning. They not only dislike the bottom-up approach to planning, but are not accustomed to it. Third, most citizens overlook opportunities to participate in the regional planning process because citizen participation has only recently been introduced and they are not accustomed to it. Consequently, although it exists in a formal sense, it is not very effective. Finally, citizen participation is permitted only at a limited number of opportunities. In the case of Chungbook, citizen participation was permitted at only 5 times during the entire planning process.

To overcome these problems, it is necessary to improve the process of citizen participation in planning. A modification of the present regional planning process in Korea could accomplish this goal. This proposal is outlined in Fig 4. Here the planning processes consist of 3 stages. The first step is the pre-planning stage, the second step is the decision-making stage, and the third step is the afterplan stage. The decision-making and after-plan stages are similar to the planning process as currently practiced. But the pre-plan stage is new.

The pre-plan stage is designed to awaken citizens to the planning process and to search for a consensus concerning issues among the citizens before the decision-making stage. The first step of the pre-plan stage is to inform citizens about the subject of the plan, its characteristics, and its function in order to create citizens' interest when the government initiates the regional development planning process. A newspaper and broadcasting campaign can be used in order to strengthen citizen participation in this stage. Although initially citizens are not really expected to suggest any proposals, this is a necessary step to activate citizen's thoughts. The next step at this stage is the "concurrence of issues". The objective here is to arrive at a mutual agreement concerning scope of the plan.

Additionally, in order to intensify citizen participation in the planning process, citizens must participate throughout the process. In other words, citizens should be involved from the initial stage to the final stage. Government agencies must deviate from their top-down approach to planning. Citizens' desire to participate must 
be activated. This could be achieved if the government would organize training programs advocating a bottom-up approach to planning based on grassroots participation since most citizens are not accustomed to citizen participation in any form.

Citizen participation should play an important role in the planning process because a plan created without the input of the affected citizens is difficult to implement successfully. One of the important lessons many developing countries are learning is that planning does not always guarantee a successful development program. The inclusion of citizens in this process can improve a plan's chances for successful implementation.

The extensive and positive participation of residents in regional development planning can have a significant impact on making sound regional plans and regional policy. Citizen participation creates a training effect for citizens since it helps them to solve their own problems in various situations. Citizens experience the dynamics of decisionmaking process and many realize the value of grassroots democracy through participation. Although strengthened citizen participation is not a panacea in planning, it can certainly play a critical role in promoting sound regional development planning in Korea.

\section{Footnotes}

1) Refer to i) The City of Seoul, The Project of Kwangiu Satellite Ciny Building. (Seoul: The City of Seoul, 1971), p. 8, and ii) Korea Times. February 4, 1987.

2) Won Kim, Urban Administration. (Seoul: ParkYoung Co., 1982), p. 346 .

3) Environmental Planning Institute, Comprehensive Chungbook Development Plan: The Interim Report, (Chungbook: Chungbook Government, 1982), pp. 12, 25.

4) Chungbook, The Report of Comprehensive Chungbook Development Plan, (Chungbook: Chungbook Government, 1982), p. 10.

5) Environmental Planning Institute, op. cit., p. 4.

6) The "new village movement" or Saemaul Undong" has brought about significant changes, physically and socially, in rural communities for the more than 10 years since its inception in 1970. It is a nationwide community development movement organized on the basis of positive participation of village members whose main purpose is to promote community development projects such as construction of roads and bridges small-scale irrigation projects, sanitary water supply projects, and production of other public goods.

7) Chungbook, op. cit., p. 5.

8) Ibid., p. 4

9) Lester W. Milbrath, "Citizen Surveys as Citizen Participation Mechanisms," The Journal of Applied Behavioral Science, (Vol. 17, No. 4, 1981), p. 481

10) For further information about advisory committee, refer to James J. Glass, "Citizen Participation in Planning: The Relationship between Objectives and Techniques," APA Journal, (Vol. 45, No. 2, April 1979), p. 186.

11) Lester W. Milbrath, op. cit., p. 482.

12) Ibid., p. 479 .

13) Desmond $M$. Connor, Citizens Participate: An Action Guide for Public Issues, (Oakville: Development Press, 1974), pp. 14-17.

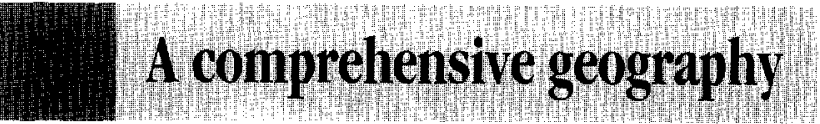

H.Lautensach

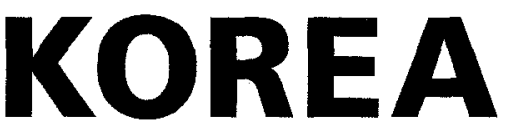

A Geography

based on the Author's Travels and Literature

Translated and edited by K. \& E. Dege,

University of Kiel, FRG

Published by Dr. W.Tietze, Geo-Wissenschaftliche GmbH, FRG

1988. XVII, 598 pp. 42 photographs, 95 diagrams, 46 tables, 1 map. Hardcover DM 162,-

ISBN 3-540-19139-9

Lautensach's Korea, dated from before the country was divided, is the most comprehensive regional geography

ever written in a Western language. A wealth of information is provided on the entire country, including the north, which has been isolated from Western contacts for nearly forty years. Following an extensive introduction into the geography, climatology, fauna and flora of the country as a whole, sixteen subregions are described in detail. In a last section, the author deals with the colonization of Korea by the Japanese and the development of the country. The Appendix comprises a very extensive bibliography of relevant literature as well as a comprehensive list of Korean geographical names. In contrast to the original German edition, the Korean pronunciation is used throughout the text. The index now includes all names with their Korean and Japanese pronunciation, as well as Chinese characters. For anyone interested in Korea, its modern development and industrialization, Lautensach's Korea provides a wealth of background information important for understanding the modern development of the country.

Price is subject to change without notice. All prices for books and journals include $7 \%$ VAT. In EC countries the local VA'T is effective.

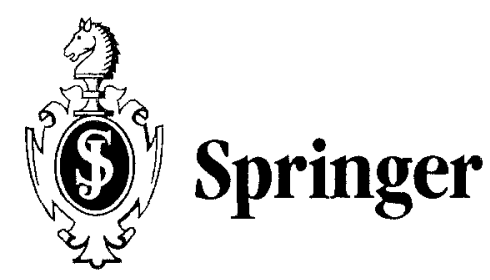

Springer-Verlag $\square$ Heidelberger Platz 3, W-1000 Berlin 33, F.R.Germany $\square 175$ Fifth Ave., New York, VY 10010, USA $\square 8$ diexandra Rd., London SW $197 \mathrm{JZ}$, England $\square 26$, rue des Carmes F.75005 Paris, France $\square 37-3$, Hongo 3-chome, Bunkyo-ku, Tokyo 113, Japan $\square$ Room 701, Mirror Tower, 61 Mody Road. Tsimshatsui, Kowloon, Hong Kong $\square$ Avinguda Diagonal, $468-4^{0} \mathrm{C}$, E-08006 Barcelona, Spain $\square$ Wesselényi u. 28, H-1075 Budapest, Hungary 